\title{
EFEKTIFITAS PENDIDIKAN KESEHATAN TENTANG KANKER PAYUDARA TERHADAP MOTIVASI MELAKUKAN SADARI PADA WANITA USIA SUBUR
}

\author{
Ditya Yankusuma ${ }^{1}$, Augustin Pramulya ${ }^{2}$
}

\begin{abstract}
The prevalence of breast cancer is quite high in Indonesia, amounting to 40 per 100.000 women (DepKes RI, 2014). While estimation of the largest number of breast cancer patients in 2013 found in Central Java is 11.511 (KemenKes RI, 2015). The results of the initial survey on Keloran villagers, obtained 1 citizen died of breast cancer. Residents encountered during the initial survey of 10 women of childbearing age said that until now had never received socialization about SADARI and had never done SADARI. Purpose of the study: to know the influence of health education about breast cancer disease to motivate to do SADARI on Women Age Fertile in Keloran Wonogiri regency.

Subjects: the population in this study were women aged between 20-45 years old, amounting to 32 people. This research method researchers used a pre-experimental design research design with the approach of one group pre test post test method.

Results: the result of paired t-test is $0.000(p<0.05)$ which statistically there is difference of mean and moderate mean of motivation. Conclusion there is an influence of health education on the motivation of women of childbearing age in Keloran Wonogiri Village.
\end{abstract}

Keywords: health education, SADARI, motivation

\section{PENDAHULUAN}

Kanker payudara adalah suatu penyakit yang disebabkan adanya pertumbuhan berlebihan atau perkembangan tidak terkontrol dari sel-sel (jaringan) payudara. Di Indonesia, penyakit kanker payudara menempati urutan kedua setelah kanker serviks (Kumalasari dan Andhyantoro, 2012).

Prevalensi penyakit kanker payudara cukup tinggi di Indonesia, sebesar 40 per 100.000 perempuan (Kemenkes RI, 2014). Sedangkan estimasi jumlah penderita kanker payudara terbesar pada tahun 2013 di temukan di Jawa Tengah yaitu sebesar 11.511 (Kemenkes RI, 2015).

Kanker payudara masih mempunyai kemungkinan besar untuk disembuhkan kalau ditemukan ketika masih pada tahap awal atau dini salah satunya dengan melakukan SADARI. Dengan demikian, penemuan kanker payudara sejak dini sangatlah penting untuk sebuah kesembuhan. Deteksi dini dilakukan dengan melakukan "pemeriksaan payudara sendiri" atau yang dikenal dengan istilah SADARI. Ini adalah pemeriksaan yang mudah dilakukan oleh setiap wanita untuk mencari benjolan atau kelainan lainnya (Purwoastuti, 2008). Pemeriksaan payudara sendiri (SADARI) sangat penting sebagai langkah awal untuk mengetahui apakah menderita kanker payudara atau tidak. Adanya informasi tentang pemeriksaan payudara sendiri dapat menambah pengetahuan wanita usia subur khususnya area payudara, sehingga menjadi motivasi para wanita untuk meningkatkan deteksi dini kanker payudara dengan melakukan SADARI (Aisyah, 2015).

Motivasi adalah dorongan yang timbul pada diri seseorang secara sadar atau tidak sadar untuk melakukan suatu tindakan dengan tujuan tertentu atau usaha-usaha 
yang dapat menyebabkan seseorang atau kelompok orang tertentu tergerak melakukan sesuatu karena ingin mecapai tujuan yang dikehendakinya atau mendapat kepuasan dengan perbuatannya (Kompri, 2016).

Pendidikan kesehatan pada hakikatnya merupakan upaya untuk membentuk budaya perilaku suatu masyarakat yang menguntungkan dan mendukung kesehatan dari masyarakat tersebut. Salah satu esensi pendidikan dan pembelajaran adalah perubahan perilaku individu yang secara keseluruhan sebagai hasil interaksi dengan lingkungan (Tim Pengembang IImu Pendidikan, 2007).

Berdasarkan hasil penelitian yang dilakukan Aisyah (2015), didapatkan hasil bahwa ada perbedaan motivasi wanita usia subur usia 20-45 tahun sebelum dan sesudah dilakukan pendidikan kesehatan tentang SADARI di Kelurahan Jebres Surakarta. Demikian halnya yang dilakukan oleh Masithoh (2015) yang mendapatkan hasil bahwa motivasi untuk melakukan pemeriksaan payudara sendiri (SADARI) sebelum pendidikan kesehatan pada wanita usia subur sebagian besar dalam kategori motivasi kurang yaitu sebanyak 32 responden $(68.1 \%)$, sedangkan setelah diberikan pendidikan kesehatan sebagian besar dalam kategori cukup yaitu sebanyak 31 responden (66.0). Jadi ada perbedaan motivasi untuk melakukan SADARI sebelum dan sesudah pendidikan kesehatan pada wanita usia subur di Desa Sukolilo RW 4 Kabupaten Pati. Hasil survei awal pada warga desa Keloran, didapatkan 1 warga meninggal karena kanker payudara. Warga yang ditemui pada saat survey awal yaitu 10 wanita dengan usia subur mengatakan bahwa sampai saat ini belum pernah mendapat sosialisasi tentang SADARI dan belum pernah melakukan SADARI.

Berdasarkan uraian di atas peneliti tertarik untuk meneliti tentang "Pengaruh Pendidikan Kesehatan tentang Penyakit Kanker Payudara terhadap Motivasi Melakukan SADARI pada Wanita Usia Subur di Desa Keloran Kabupaten Wonogiri".

\section{TUJUAN PENELITIAN}

Untuk mengetahui pengaruh pendidikan kesehatan tentang penyakit kanker payudara terhadap motivasi melakukan SADARI pada Wanita Usia Subur di Kelurahan Keloran Kabupaten Wonogiri.

\section{METODE/DESAIN PENELITIAN}

Desain dari penelitian ini menggunakan pre experimental design dengan pendekatan metode one group pre test post test design. Dalam penelitian ini dilakukan pre test dahulu sebelum diberikan intervensi kemudian setelah diberikan intervensi dilakukan post test.

\section{POPULASI, SAMPEL, DAN TEKNIK SAMPLING}

Populasi dalam penelitian ini adalah wanita usia subur usia 20-45 tahun yang berjumlah 32 orang.

Berdasarkan jumlah populasi yang telah ditetapkan sebesar 32 orang, maka sampel yang digunakan adalah semua responden yang ada dalam populasi tersebut.

Pada penelitian ini, peneliti menggunakan teknik sampling jenuh yaitu pengambilan sampel berdasarkan semua jumlah populasi yang ada. 
HASIL PENELITIAN

1. Karakteristik Responden

Tabel 1.

Karakteristik Responden

\begin{tabular}{lccc}
\hline Karakteristik & Kategori & $\mathrm{f}$ & $\%$ \\
\hline Umur & $20-25$ & 9 & 28.1 \\
(tahun) & $26-30$ & 2 & 6.3 \\
& $31-35$ & 5 & 15.6 \\
& $36-40$ & 11 & 34.4 \\
& $41-45$ & 5 & 15.6 \\
Tingkat & SMP & 6 & 18.7 \\
Pendidikan & SMA & 18 & 56.3 \\
& PT & 8 & 25 \\
Sumber & Tidak & 28 & 87.5 \\
Informasi & pernah & 28 & 0 \\
& Buku & 0 & 0 \\
& Majalah & 1 & 3.13 \\
& Internet & 2 & 6.25 \\
& Lain-lain & 1 & 3.13 \\
\hline
\end{tabular}

Dari tabel di atas dapat diketahui:

a. Responden paling besar (34.4\%) berada pada kelompok umur 36-40 tahun dan responden paling sedikit $(6.3 \%)$ berada pada kelompok umur 26-30 tahun.

b. Sebagian besar responden berpendidikan SMA (56.3\%).

c. Sebagian besar responden belum pernah mendapatkan informasi terkait deteksi dini kanker payudara (87.5\%).

2. Distribusi Frekuensi Motivasi Wanita Usia Subur Sebelum dilakukan Pendidikan Kesehetan

Tabel 2.

Distribusi Frekuensi Motivasi

Sebelum dilakukan

Pendidikan Kesehatan

\begin{tabular}{lcc}
\hline Motivasi & $\mathrm{f}$ & $\%$ \\
\hline Tinggi & 3 & 9.37 \\
Rendah & 29 & 90.63 \\
& & 100 \\
\hline Jumlah & 32 & 5.00 \\
Mean & & 5.00 \\
Median & & 2.383 \\
Std & & \\
\hline
\end{tabular}

Dari tabel di atas ditemukan bahwa mayoritas responden memiliki motivasi yang rendah dalam melakukan SADARI yaitu sebesar $90.63 \%$ responden sebelum dilakukan pendidikan kesehatan tentang kanker payudara. Nilai rata-rata motivasi sebelum pendidikan kesehatan adalah sebesar 5.00 dan termasuk kategori rendah.

3. Motivasi Setelah Dilakukan Pendidikan Kesehatan

Tabel 3.

Distribusi Frekuensi Motivasi Wanita Usia Subur Setelah dilakukan Pendidikan Kesehatan

\begin{tabular}{lcc}
\hline Motivasi & $f$ & $\%$ \\
\hline Tinggi & 32 & 100 \\
Rendah & 0 & 0 \\
\hline Jumlah & 32 & 100 \\
\hline Mean & \multicolumn{2}{c}{13.41} \\
Median & \multicolumn{2}{c}{13.50} \\
Std & \multicolumn{2}{c}{1.563} \\
\hline
\end{tabular}

Dari tabel di atas ditemukan bahwa semua responden mempunyai motivasi tinggi dalam melakukan SADARI setelah dilakukan pendidikan kesehatan yaitu sebesar $100 \%$. Nilai rata-rata motivasi sesudah pendidikan kesehatan adalah sebesar 13.41 dan termasuk kategori tinggi.

4. Pengaruh Pendidikan Kesehatan terhadap Motivasi Wanita Usia Subur dalam Melakukan SADARI

Tabel 4.

Pengaruh Pendidikan

Kesehatan terhadap Motivasi Melakukan SADARI

\begin{tabular}{|c|c|c|c|}
\hline \multicolumn{2}{|c|}{ Mean } & \multirow{2}{*}{ t-test } & \multirow{2}{*}{ Ket } \\
\hline Pre & Post & & \\
\hline 5.00 & 13.41 & 0.000 & $\begin{array}{c}\text { Ada } \\
\text { pengaruh }\end{array}$ \\
\hline
\end{tabular}

Hasil Uji Paired t-test adalah 0.000 ( $\mathrm{p}<0.05$ ) yang secara statistik terdapat perbedaan rerata motivasi yang bermakna sebelum dan sesudah pemberian pendidikan kesehatan. 


\section{PEMBAHASAN}

1. Motivasi Wanita Usia Subur Melakukan SADARI Sebelum Pemberian Pendidikan Kesehatan

Hasil penelitian yang didapatkan bahwa tingkat motivasi responden mayoritas rendah yaitu sebesar $90.63 \%$. Dibuktikan dengan jawaban kuesioner dari responden yang menjawab bahwa responden tidak pernah mencoba mencari informasi tentang SADARI, tidak ada niat dari responden untuk melakukan SADARI, responden tidak meyakini bahwa SADARI penting dalam pencegahan kanker payudara. Tingkat pendidikan yang sebagian besar SMA menjadi salah satu faktor yang mempengaruhi kurangnya pengetahuan wanita usia subur (WUS) tentang SADARI. Selain itu juga dari faktor lain seperti kurang terpaparnya terhadap informasi. Dari hasil penelitian, mayoritas responden belum pernah mendapatkan penyuluhan kesehatan tentang deteksi dini kanker payudara yaitu sebesar $87.5 \%$.

Responden mendapatkan informasi hanya mengenai penyakit kanker payudara dan itupun tidak detail. Hal ini sesuai dengan pendapat Notoatmodjo (2007), menyatakan bahwa semakin rendah pendidikan seseorang, maka akan semakin sulit menerima informasi, dan akhirnya semakin sedikit pengetahuan yang dimilikinya. Individu yang mempunyai sedikit pengetahuan cenderung bersikap dan berperilaku yang tidak sesuai. Sikap dan perilaku yang ini pada akhirnya menyebabkan seseorang tidak memiliki motivasi untuk melakukan deteksi dini kanker payudara. Pengetahuan sangat erat hubungannya dengan pendidikan, dimana diharapkan bahwa dengan pendidikan yang tinggi maka orang tersebut akan semakin luas pengetahuannya. Semakin luas pengetahuan individu maka akan menimbulkan motivasi seseorang terhadap sesuatu hal yang dianggap berguna bagi dirinya (Wawan dan Dewi, 2011).

2. Pengaruh Pendidikan Kesehatan terhadap motivasi Wanita Usia Subur Melakukan SADARI

Pendidikan kesehatan ini dilakukan dengan menggunakan media power point dengan metode ceramah dan tanya jawab. Pendidikan kesehatan ini dilakukan satu kali yang sebelumnya telah dilakukan pre tes terlebih dahulu kemudian setelah 2 minggu kemudian baru dilakukan post test.

Setelah dilakukan pendidikan kesehatan selama \pm 30 menit, didapatkan hasil bahwa semua motivasi dari responden juga meningkat yaitu $100 \%$, hal ini dapat dilihat dari nilai rata - rata responden sesudah diberikan pendidikan kesehatan sebesar 13.41 dan termasuk dalam kategori tinggi. Dilihat dari kuesioner, bahwa responden sudah mempunyai niat untuk melakukan secara rutin teknik SADARI dengan benar.

Motivasi adalah suatu dorongan misalnya ide, emosi atau kebutuhan fisik yang menyebabkan seseorang mengambil suatu tindakan (Hamzah, 2014). Motivasi merupakan hal yang menyebabkan dan mendukung tindakan atau perilaku seseorang. Motivasi responden dalam deteksi kanker payudara meningkat karena pendidikan 
kesehatan yang $\begin{array}{r}\text { sudah } \\ \text { sehingga }\end{array}$
didapatkan
pengetahuan responden pun
meningkat. Hal ini sesuai
dengan pendapat Notoatmodjo
(2007), bahwa pengetahuan
merupakan domain yang sangat
$\begin{aligned} & \text { penting dalam membentuk } \\ & \text { tindakan }\end{aligned}$

Pengetahuan responden yang kurang bisa disebabkan karena pendidikan responden yang rendah atau karena kurang terpapar dengan informasi tentang deteksi kanker payudara. Pendidikan atau promosi kesehatan adalah suatu bentuk intervensi atau upaya yang ditujukan kepada perilaku, agar perilaku tersebut kondusif untuk kesehatan. Dengan perkataan lain, promosi kesehatan mengupayakan agar perilaku individu, kelompok, atau masyarakat mempunyai pengaruh positif terhadap pemeliharaan dan peningkatan kesehatan Notoatmodjo (2007). Hasil uji Sample Paired T-Test didapatkan hasil bahwa nilai significancy 0.000 ( $p<0.05)$ yang berarti terdapat perbedaan rerata motivasi yang bermakna sebelum dan sesudah pemberian pendidikan kesehatan. Adanya perbedaan yang signifikan dari pendidikan kesehatan ini terjadi karena pendidikan kesehatan telah mampu memperluas wawasan, pengetahuan dan ketrampilan wanita usia subur dalam hal deteksi dini tanda dan gejala kanker payudara. Melalui pendidikan kesehatan akan terjadi proses komunikasi dan pertukaran informasi antara petugas kesehatan dengan adanya kelompok sasaran. Proses komunikasi dan pertukaran informasi ini akan berjalan efektif apabila pendidikan kesehatan direncanakan dengan baik, menggunakan metode yang tepat dengan dukungan media atau alat peraga yang sesuai. Promosi kesehatan mengupayakan agar perilaku individu, kelompok, atau masyarakat mempunyai pengaruh positif terhadap pemeliharaan dan peningkatan kesehatan (Notoatmodjo, 2007). Hasil ini sesuai dengan penelitian yang dilakukan oleh Sari (2016), yang berjudul pengaruh pendidikan kesehatan tentang pemeriksaan payudara sendiri terhadap pengetahuan dan motivasi melakukannya pada wanita usia 30-50 tahun di Desa Joho Mojolaban dan didapatkan hasil bahwa uji beda pengetahuan menunjukkan $p$ value $=0.001$ dan motivasi menunjukkan $p$-value $=0.002$. Dari hasil penelitian ini dapat disimpulkan bahwa pendidikan kesehatan tentang pemeriksaan payudara sendiri berpengaruh terhadap pengetahuan dan motivasi melakukannya.

Begitu juga penelitian yang dilakukan oleh Suhita (2008), yang berjudul pengaruh health education terhadap pengetahuan dan sikap wanita dewasa tentang sadari dalam upaya deteksi dini ca mammae di Kediri, di dapatkan hasil bahwa nilai $t$ sebesar 16.321 dengan nilai $p$-value sebesar 0.00 kurang dari nilai $\alpha$ yang berarti ada pengaruh health education terhadap peningkatan pengetahuan dan sikap wanita dewasa tentang sadari dalam upaya deteksi dini ca mammae di Kediri.

Hasil penelitian ini memberikan bukti bahwa promosi kesehatan dapat meningkatkan pengetahuan responden sehingga mampu merubah sikap dan perilaku responden 
untuk lebih baik dalam pencegahan suatu penyakit.

\section{KESIMPULAN}

1. Motivasi wanita usia subur di Desa Keloran Wonogiri untuk melakukan SADARI sebelum dilakukan pemberian pendidikan kesehatan adalah termasuk rendah dengan nilai rata-rata motivasi sebesar 5.00.

2. Motivasi wanita usia subur di Desa Keloran Wonogiri untuk melakukan SADARI setelah pemberian pendidikan kesehatan adalah termasuk tinggi dengan nilai rata-rata motivasi sebesar 13.41.

3. Ada pengaruh pendidikan kesehatan terhadap motivasi wanita usia subur di Desa Keloran Wonogiri dengan nilai significancy $0.000 \quad(p<0.05)$.

\section{SARAN}

1. Bagi Dinas Kesehatan disarankan untuk tetap melakukan pembinaan bagi tenaga kesehatan di masyarakat agar memberikan penyuluhan terkait deteksi dini kanker payudara.

2. Di sarankan warga masyarakat untuk melakukan deteksi dini kanker payudara secara rutin dan dapat mencegah kanker payudara dengan mengatur pola hidup yang sehat.

3. Diharapkan dapat dijadikan data awal untuk penelitian selanjutnya.

\section{DAFTAR PUSTAKA}

Aisyah, S.N. 2015. Perbedaan Motivasi Sebelum dan Sesudah Pemberian Pendidikan Kesehatan tentang SADARI pada Usia 20-40 tahun di Keluarahan Jebres Surakarta.

Http://perpusnwu.web.id. Diunduh Pada Tanggal 9 Oktober 2016.
Hamzah. 2014. Teori Motivasi dan

Pengukurannya Analisis di Bidang Pendidikan. Bumi Aksara, Jakarta.

Kemenkes RI. 2014. Hilangkan Mitos Tentang Kanker. Jakarta: Pusat Komunikasi Publik Sekretariat Jenderal Kementerian Kesehatan RI. . 2015. Situasi Penyakit Kanker. Infodatin, Jakarta.

Kompri. 2016.

Motivasi Pembelajaran Perspektif Guru dan Siswa. Remaja Rosdakarya, Bandung.

Kumalasari, I. dan I. Adhyantoro. 2012. Kesehatan Reproduksi untuk Kebidanan dan Keperawatan. Salemba Medika, Jakarta.

Masithoh, A. R. 2015. Motivasi untuk Melakukan Pemeriksaan Payudara Sendiri (SADARI) Sebelum dan Sesudah Pendidikan Kesehatan tentang Kanker Payudara pada Wanita Usia Subur. Http://ejurnal.stikesmuhkudus. ac.id. Diunduh Pada Tanggal 9 Oktober 2016.

Notoatmodjo, S. 2007. Promosi Kesehatan dan IImu Perilaku. Rineka Cipta, Jakarta.

Purwoastuti, E. 2008. Kanker Payudara. Kanisius, Yogyakarta.

Sari, A. C. 2016. Pengaruh Pendidikan Kesehatan tentang Pemeriksaan Payudara Sendiri terhadap Pengetahuan dan Motivasi Melakukannya pada Wanita Usia 30-50 Tahun di Desa Joho Mojolaban.

Http://eprints.ums.ac.id.

Diunduh Pada Tanggal 9 Oktober 2016.

Suhita, B. M. 2008. Pengaruh Health Education terhadap Pengetahuan dan Sikap Wanita Dewasa tentang SADARI dalam Upaya Deteksi 
Dini Ca. Mammae di Kediri.

Http://eprints.uns.ac.id.

Diunduh Pada Tanggal 9

Oktober 2016.

Tim Pengembang Ilmu Pendidikan

FIP-UPI. 2007. IImu dan Aplikasi Pendidikan. PT. Imperial Bhakti Utama, Jakarta.

Wawan, A. dan M. Dewi. 2011. Teori dan

Pengukuran

Pengetahuan, Sikap dan Perilaku Manusia. Nuha Medika, Yogyakarta.

${ }^{1}$ Dosen Akper Panti Kosala

Surakarta

${ }^{2}$ Mahasiswa Akper Panti Kosala

Surakarta 